\title{
Integrated psychological treatment for substance use and co-morbid anxiety or depression vs. treatment for substance use alone. A systematic review of the published literature Morten Hesse
}

Address: University of Aarhus, Centre for Alcohol and Drug Research, Artillerivej 90, 2300 Copenhagen S, Denmark

Email: Morten Hesse - mh@crf.au.dk

Published: 20 February 2009

BMC Psychiatry 2009, 9:6 doi:10.1 186/147|-244X-9-6

This article is available from: http://www.biomedcentral.com/I47I-244X/9/6

(c) 2009 Hesse; licensee BioMed Central Ltd.

This is an Open Access article distributed under the terms of the Creative Commons Attribution License (http://creativecommons.org/licenses/by/2.0), which permits unrestricted use, distribution, and reproduction in any medium, provided the original work is properly cited.
Received: 9 October 2008

Accepted: 20 February 2009

\begin{abstract}
Background: There is an increasing consensus in favour of integrated treatment of substance use disorders and co-morbid conditions, such as depression or anxiety. However, up till now no systematic reviews have been published.

Methods: Based on a systematic search of MedLine and Psychlnfo, 9 trials of integrated treatment for depression or anxiety plus substance use disorder were identified. Where possible, metaanalyses were carried out, using random effects models.

Results: Meta-analyses were carried out for integrated treatment for depression and substance use disorders on a number of outcomes. No meta-analysis could be carried out for integrated treatment for anxiety and substance use disorders, due to multivariate reporting of outcomes in original articles. Integrated treatment for depression and substance abuse produced significant effects on percent days abstinent at follow-up. Differences in retention and symptoms were nonsignificant, but favoured the experimental condition. For studies of integrated treatment for comorbid anxiety disorders and substance use disorders, no meta-analysis could be carried out. Several studies of integrated treatment for anxiety and substance use disorders reported that patients assigned to substance use treatment only fared better.

Conclusion: Psychotherapeutic treatment for co-morbid depression and substance use disorders is a promising approach, but is not sufficiently empirically supported at this point. Psychotherapeutic treatment for co-morbid anxiety and substance use disorders is not empirically supported. There is a need for more trials to replicate the findings from studies of integrated treatment for depression and substance use disorders, and for the development of new treatment options for co-morbid anxiety and substance use disorders.
\end{abstract}

\section{Background}

The prevalence of other psychiatric diagnoses among those with substance-related disorders is notable $[1,2]$. Around $25 \%$ of people in the community in the United States with alcohol dependence and around $50 \%$ of people with drug dependence have co-morbid depression [2].
Anxiety disorders can be diagnosed in around $25 \%$ of alcohol dependent people and $43 \%$ of drug dependent people [2]. Jané-Llopis and Matytsina reviewed surveys from around the world, and found that studies have shown converging evidence for high co-morbidity, recommending that integrated services should be available for 
patients with co-morbid psychiatric conditions and substance use disorders [1].

Co-morbid psychiatric diagnoses accompanying alcohol addiction, such as severe cases of anxiety or depression, may have a negative impact on quality of life, and on functioning and ability to respond to treatment $[3,4]$.

However, little is known about how to effectively treat these common co-morbidities in substance abusers. Tiet and Mausbach reviewed the literature on integrated treatment, and found that few studies have assessed the effectiveness of integrated treatments for substance use disorders with co-morbid disorders [5].

There is currently some evidence that medications can be effective for co-morbid depression and substance use disorders $[6,7]$.

Among non-substance using patients with anxiety and depression, there is a substantial amount of evidence supporting the efficacy of psychotherapies. For instance, there is robust evidence that cognitive-behavioural therapies can be effective for anxiety disorders [8], and short-term psychodynamic therapy as well as cognitive-behavioural therapy has been shown to be effective for mood disorders such as depression and dysthymia [9].

There is less evidence that non-somatic treatments such as psychotherapy or behaviour therapy is effective for comorbid depression and substance use disorders (SUD), and there are no empirically supported treatments for comorbid anxiety and substance use disorders.

In principle, psychotherapies could be useful in at least three ways: psychotherapies could alleviate the symptoms of depression or anxiety, thereby improving the patients' quality of life. They could help patients understand their co-morbidity better, so that the patients were able to understand the link between psychiatric symptoms and relapse, thereby enhancing better coping with urges and cravings, and thereby directly reduce substance use independently of effects on depression and anxiety. And finally, they could improve both. In this review, both outcomes in terms of substance use and in terms of symptoms are considered. For any review that combines data, it is a great challenge when the measures representing related outcomes vary. The choice of the reviewer may be to exclude a substantial proportion of the literature in order to obtain a homogeneous outcome measure, or to combine various outcomes. Both decisions lead to advantages and disadvantages for the outcomes of the review. Excluding a large number of studies may mean that clinically important information is lost. Combining very different measures may result in the inclusion of measures that lack validity and reliability, thereby leading to the wrong conclusions. However, what is available to the reviewer is not known until the literature search has been conducted. For this reason, there is a degree of compromise involved.

\section{Methods}

A comprehensive search of Medline and PsycINFO was carried out, combining terms reflecting depression 1 . ("mood" or "depression" or "depressive"), or 2. ("anxiety") with terms reflecting substance use disorders ("substance abuse" or "substance dependence" or "cocaine" or "heroin" or "cannabis" or "alcohol"), and terms reflecting randomized controlled designs ("randomized" or "control group") and terms reflecting non-somatic interventions ("behavioral therapy" or "psychotherapy" or "psychosocial intervention"). Additional searchers using the same search-words were carried out on the Cochrane register of clinical trials and CINAHL. References of included studies were hand-searched, and registers of clinical trials were searched (Clinical Trials, Current Controlled Trials, controlled-trials.com, National Health Service Research and Development Health Technology Assessment Programme (HTA), National Institute of Health, ClinicalTrials.gov). Additional searches were also carried out using "MDMA" as a keyword, but no further studies were identified.

\section{Inclusion criteria}

All patients in the sample had substance use disorders. Only adults included in the study. Patients in the sample had been selected for depressive or anxiety symptoms or a diagnosis of depression or anxiety. The study compared an integrated non-somatic treatment for both substance use disorders and depression or anxiety with a treatment programme solely focusing on the substance use disorder. The study employed a randomized controlled design. Data at post-treatment and/or at follow-up on retention, psychiatric symptoms or substance use outcomes. Only published studies were included. No language restrictions were used.

\section{Exclusion criteria}

Interventions with a mixture of somatic and non-somatic treatments (i.e. where patients were randomized to a combination of pharmacotherapy and psychotherapy vs. placebo). Note that studies where subjects who were randomized to non-somatic treatments were included, even if they were allowed to receive pharmacotherapy during the trial. Studies were excluded only if the experimental condition differed from the control condition in terms of medication status, or if schizophrenia spectrum disorder or personality disorder required for inclusion into study. 


\section{Data extraction and analysis}

Data were extracted by the author alone. In the present review, data were analysed using the following outcome measures:

\section{Substance use}

As all studies that reported substance use outcomes reported percent days abstinent (PDA), and as PDA is a widely used and well-validated measure of substance use severity, this measure was chosen as the indicator of substance use, and the Weighted Mean Difference (WMD) between the control and experiment group was estimated at the follow-up point most commonly reported ( 6 months).

\section{Interviewer-rated symptoms}

As all studies that reported interviewer-rated symptoms used the Hamilton Rating Scale for Depression (HRSD), and as the HRSD is a widely used and well-validated measure of depression, this measure was chosen as the outcome measure for interviewer-rated symptoms, and the WMD between the control and experiment group was estimated at the follow-up points.

\section{Completion of treatment}

From studies that reported differential retention in treatment, the proportion of patients who completed the experimental and control treatment was extracted.

Meta-analyses were conducted using RevMan 4.1 from Cochrane Collaboration, and are presented in RevMan forest plots. For Hamilton Rating Scales and Percent Days Abstinent, Weighted Mean Differences [WMD] were calculated. For all self-report measures of anxiety and all other substance use outcomes combined, Standardized Mean Differences [SMD] were calculated. For retention in treatment, Odds Ratio [OR] was calculated. For all metaanalyses, random effects models were used, as the studies were heterogeneous both with regard to interventions and types of patients. For all outcomes, the $\mathrm{I}^{2}$ statistic was reported. The $\mathrm{I}^{2}$ represents the degree of heterogeneity and can range from 0 to 1 . The group that first presented the $\mathrm{I}^{2}$ statistic tentatively suggested that values of $25 \%, 50 \%$, and $75 \%$ represent low, moderate, and high heterogeneity [10]. The $I^{2}$ statistic represents the extent of heterogeneity, rather than the statistical significance of heterogeneity.

\section{Results}

In Medline, this search resulted in 118 hits, and in PsycINFO, it resulted in 155 hits. Reviews and titles suggesting non-somatic treatments for co-morbid anxiety or depression and substance use disorders were retrieved. Reference lists of reviews and published studies were examined, and studies reporting randomized controlled trials were included. Searches of Cochrane register of clinical trials and CINAHL did not provide additional studies.

Of these reported articles, ten randomized controlled trials that satisfied the inclusion criteria were identified. Five studies were identified that compared integrated treatments for mood disorders and substance use disorders with treatment only for substance use disorders, and five studies that compared integrated treatment for anxiety and substance use disorders with treatments for only substance use disorders.

\section{Description of studies}

Five randomised studies provided manual-guided treatment for co-morbid depression or depressive symptoms and substance use disorders [11-15]. Details of the studies are provided in table 1 and 2 .

The studies are small, with only 223 patients randomized in total. One study used a rarely studied model called selfexamination therapy [11], two studies assigned patients to cognitive-behavioural therapy or control [12,13], one study assigned patients to a mainly behavioural intervention [14], and one study assigned patients to interpersonal psychotherapy vs. placebo [15].

Bowman and colleagues compared Self-examination therapy with an attention placebo treatment for co-morbid depression in patients with substance use disorders and co-morbid depressive symptoms during inpatient treatment [11]. In Self-examination therapy, "people are given a booklet which uses a flow chart format and encourages them to: (a) determine what matters to them, (b) think less negatively about things that do not matter to them, (c) invest their energy in things that are important to them, and (d) accept situations they cannot change." [[11], p. 130]. The authors did not report the number of patients receiving medication.

Richard A. Brown and colleagues compared cognitive therapy for depression with relaxation training as part of a partial hospitalization program for alcohol dependence [12]. The cognitive therapy condition, called the "Coping with depression course", incorporated training in depression-relevant skills such as mood monitoring, pleasant activities, constructive thinking, and social skills. [12]. Nearly half the patients (45\%) received medication.

Sandra A. Brown and colleagues compared integrated cognitive therapy for depression and substance dependence with Twelve Steps Facilitating therapy [13]. Patients were recruited from a dual diagnosis clinic, and all patients were diagnosed using a structured interview (the CIDI). 
Table I: Characteristics of studies integrating treatments for depression and substance use disorders

\begin{tabular}{|c|c|c|c|c|c|}
\hline & Type of participants & $\begin{array}{l}\text { Proportion receiving } \\
\text { antidepressants }\end{array}$ & $\begin{array}{l}\text { Criterion for } \\
\text { depression }\end{array}$ & Interventions & Outcomes \\
\hline Bowman et al., 1996 [II] & $\begin{array}{l}\text { Male substance } \\
\text { abusers in an inpatient } \\
\text { treatment program. }\end{array}$ & Not reported & $\begin{array}{l}\text { Elevated symptoms } \\
\text { (MMPI or MCMI } \\
\text { dysthymia) }\end{array}$ & $\begin{array}{l}\text { Self examination } \\
\text { therapy versus } \\
\text { current events } \\
\text { group }\end{array}$ & $\begin{array}{l}\text { SCL-90-R depressive } \\
\text { symptoms post- } \\
\text { treatment, retention }\end{array}$ \\
\hline Brown et al., 1997 [13] & $\begin{array}{l}\text { Alcohol dependent } \\
\text { patients recruited } \\
\text { from a day partial } \\
\text { hospital program }\end{array}$ & $45 \%$ & $\begin{array}{l}\text { Elevated symptoms } \\
\text { (BDI) }\end{array}$ & $\begin{array}{l}\text { Coping with } \\
\text { depression versus } \\
\text { relaxation training }\end{array}$ & $\begin{array}{l}\text { HRSD and BDI post- } \\
\text { treatment, Percent } \\
\text { Days Abstinence at } \\
\text { follow-up }\end{array}$ \\
\hline Brown et al., 2006 [12] & $\begin{array}{l}\text { Alcohol dependent } \\
\text { patients recruited } \\
\text { from a dual diagnosis } \\
\text { program }\end{array}$ & $97 \%$ & $\begin{array}{l}\text { CIDI major } \\
\text { depressive disorder }\end{array}$ & $\begin{array}{l}\text { Integrated cognitive } \\
\text { behavioural therapy } \\
\text { versus Twelve Steps } \\
\text { Facilitating therapy }\end{array}$ & $\begin{array}{l}\text { HRSD and Percent } \\
\text { Days Abstinence post- } \\
\text { treatment and at } \\
\text { follow-up, and } \\
\text { retention }\end{array}$ \\
\hline Daughters et al., 2008 [14] & $\begin{array}{l}\text { Inpatients dependent } \\
\text { on various substances }\end{array}$ & $10 \%$ & $\begin{array}{l}\text { Elevated symptoms } \\
\text { (BDI) }\end{array}$ & $\begin{array}{l}\text { LETs act versus } \\
\text { treatment as usual }\end{array}$ & $\begin{array}{l}\text { HRSD and BDI post- } \\
\text { treatment and } \\
\text { retention }\end{array}$ \\
\hline Markowitz et al, 2008 [15] & $\begin{array}{l}\text { Patients recruited } \\
\text { through flyers and } \\
\text { advertising }\end{array}$ & $0 \%$ & SCID Dysthymia & $\begin{array}{l}\text { Interpersonal } \\
\text { therapy versus brief } \\
\text { supportive } \\
\text { psychotherapy }\end{array}$ & HRSD, BDI, and PDA \\
\hline
\end{tabular}

Almost all (97\%) patients received pharmacotherapy for depression.

Daughters and colleagues provided a brief behavioural activation therapy for patients with co-morbid depression and illicit drug use. The program was called Life Enhancement Treatment for Substance Use (LETS Act) [14]. The treatment ran over 6 sessions, plus optional maintenance sessions, and involved among other things defining life goals, identifying relevant activities, self-monitoring and progressive muscle relaxation.

Finally, Markowitz and colleagues allocated patients with dysthymia and alcohol problems to interpersonal psychotherapy or supportive psychotherapy.

\section{Meta-analyses}

In terms of outcomes measured as depressive symptoms, the results of the meta-analyses are shown in figures 1,2 , 3 and 4 .

Four studies reported Hamilton Rating Scale for Depression outcomes at post-treatment [HRSD] [12-15]. The combined effect was -4.6 points on the HRSD for experimental condition compared with control (95\% confidence interval -7.4 to 1.7). There was significant and moderately high heterogeneity in the outcome (I2 $=0.61$, $\mathrm{p}=0.05)$.

Four studies reported self-report questionnaire outcomes for depression $[11,12,14,15]$. The combined effect was $\mathrm{d}$ $=-0.58(95 \%$ confidence interval -1.10 to -0.06$)$. Heterogeneity was not significant and low to moderate $\left(\mathrm{I}^{2}=0.46\right.$, $\mathrm{p}=0.14)$.

Three studies reported percent days abstinent after treatment at follow-up $[12,13,15]$. The combined effect was a reduction of 14.13 in percent days abstinent for the experimental condition (95\% confidence interval 2.14 to 26.12, $\mathrm{p}=0.02)$. Heterogeneity was low $\left(\mathrm{I}^{2}=0.17, \mathrm{p}=\right.$ $0.30)$.

Three studies reported drop-out from treatment $[11,13,14]$. The pooled effect size was 0.67 (95\% confidence interval 0.31 to $1.49, \mathrm{p}=0.33$ ).

Table 2: Number randomized and followed up in included studies

\begin{tabular}{lrr}
\hline & Number randomized (experimental/control) & Number followed (experimental/control) \\
\hline Bowman et al., $1996[11]$ & $14 / 14$ & $11 / 11$ \\
Brown et al., $1997[13]$ & $19 / 16$ & $18 / 15$ \\
Brown et al., 2006 [12] & $48 / 42$ & $28 / 18$ \\
Daughters et al., 2008 [14] & $22 / 22$ & $20 / 19$ \\
Markowitz et al, 2008 [15] & $14 / 12$ & $8 / 10$ \\
\hline
\end{tabular}




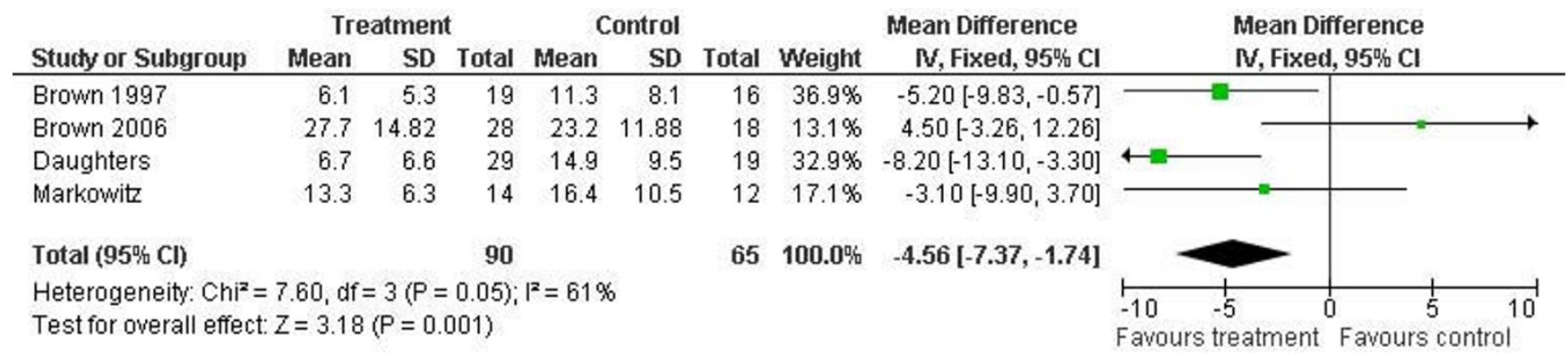

\section{Figure I}

Hamilton Rating Scale for Depression outcomes. Notes: SD: Standard deviation. Z is the Zeta statistic for significance of pooled effect size. $\mathrm{I}^{2}$ is the degree of heterogeneity of the effect size. Cl: Confidence interval.

\section{Integrated treatment for anxiety and substance use disorders versus treatment for substance use disorders alone}

Five trials have been published of the treatment of comorbid anxiety and substance dependence, three targeting alcohol dependence [16-18], and two targeting mixed populations of drug and alcohol abusers [19,20]. All studies have assigned patients to variants of cognitive-behavioural interventions.

As two of the five trials reported only multivariate outcomes, no meta-analysis was conducted $[16,17]$. Instead, the findings will be reviewed in the following.

Bowen and colleagues randomly assigned inpatients to either alcoholism treatment alone or to alcoholism treatment plus cognitive-behavioural therapy for co-morbid anxiety [16]. The treatment group received 12 hours of CBT for panic disorder in addition to the regular 4-week alcoholism treatment program, and the control group received only the regular program. No treatment group effects were observed on social anxiety or alcohol drinking indices.
Fals-Stewart and Schafer assigned patients in a therapeutic community with obsessive-compulsive disorder (OCD) to a control group, progressive muscle relaxation, or individual behaviour therapy for OCD [19]. Patients assigned to OCD treatment had lower NIMH Obsessive-compulsive scale scores at post-treatment and 12 months followup than the patients in the other groups, and a higher proportion of these patients remained abstinent (11 of 19, vs. 11 of 38$)$.

Randall and colleagues randomly assigned patients to alcoholism treatment alone, or to alcoholism treatment plus CBT for social anxiety disorder [17]. The findings indicated that anxiety outcomes were similar, but that alcoholism treatment alone was superior in terms of drinking outcomes. The treatment sessions were longer for the integrated treatment (90 minutes versus $60 \mathrm{~min}$ utes).

Schadé and colleagues randomly assigned patients to either treatment for alcoholism alone or treatment for anxiety plus alcoholism in weekly 60-minutes therapy sessions [18]. No significant differences were found for

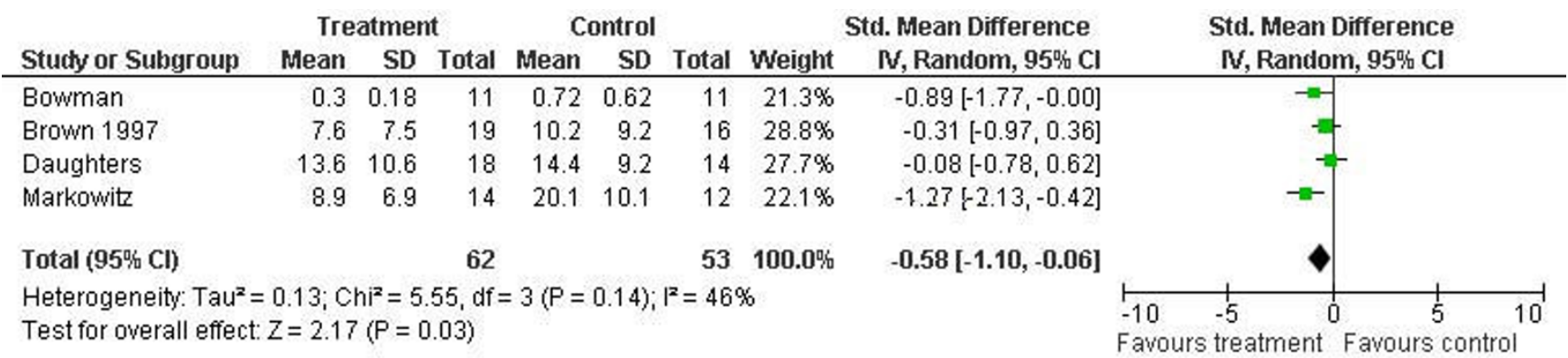

\section{Figure 2}

Self-reported depressive symptoms outcome (SCL-90 or BDI). Notes: SD: Standard deviation. Z is the Zeta statistic for significance of pooled effect size. $\mathrm{I}^{2}$ is the degree of heterogeneity of the effect size. $\mathrm{Cl}$ : Confidence interval. 


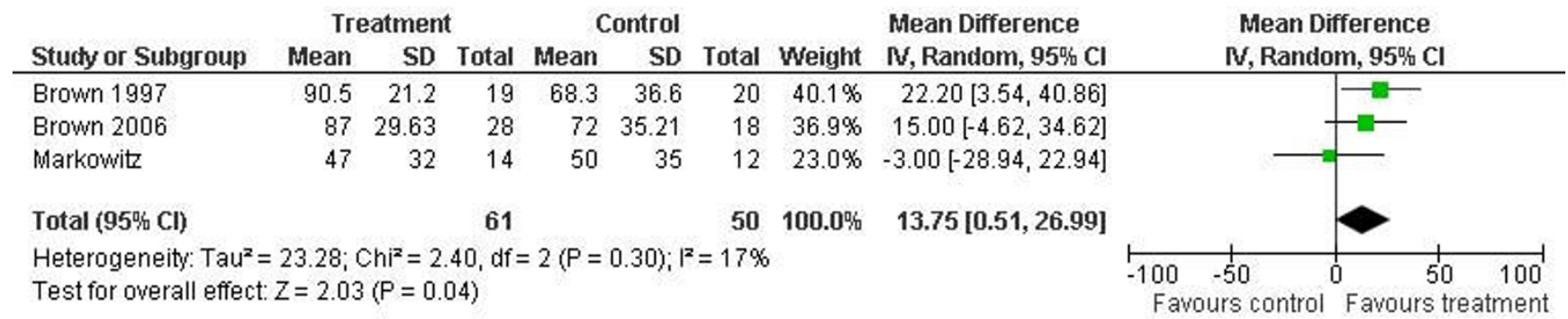

Figure 3

Percent days abstinent outcomes. Notes: SD: Standard deviation. Z is the Zeta statistic for significance of pooled effect size. $\mathrm{I}^{2}$ is the degree of heterogeneity of the effect size. $\mathrm{Cl}$ : Confidence interval.

drinking outcomes, but anxiety reductions were significantly higher for the integrated treatment group.

Hien and colleagues assigned patients to either treatment as usual in the community, cognitive relapse prevention or a specialized PTSD program, "Seeking Safety", a shortterm, manualized cognitive-behavioural treatment that simultaneously addresses trauma and substance abuse. While both intervention groups fared better than the control group, the results did not favour the Seeking Safety intervention over relapse prevention, with overall slightly better outcomes with relapse prevention [20].

\section{Discussion}

The present meta-analysis showed that integrated psychosocial treatment for depression and substance use disorders is a promising approach for patients with this comorbidity. The analyses favoured integrated treatment over single-focus treatments for percent days abstinent, depressive symptoms and retention in treatment, although percent days abstinent was the only statistically significant finding, and substantial heterogeneity was observed in several outcomes.
The meta-analyses conducted for integrated non-somatic treatment for co-morbid substance use disorders and depression indicated that while in general, outcomes favoured an integrated treatment, the difference was statistically significant for only one out of four selected outcomes (percent days abstinent at follow-up). Thus, while integrated treatment for depression and substance use disorders are promising, additional studies are needed. Also, given the small sample sizes in the studies, a risk exists that negative studies of similar have gone unpublished. The number of studies that could be included was not sufficient to conduct more formal analyses of publication bias.

\section{Quality and variability of published studies}

A substantial improvement in the reporting of clinical trials is expected with the endorsement of the CONSORT statement [21]. The CONSORT statement involves the reporting of data, including the description of study, methods and outcome. None of the included studies adhered to the CONSORT statement [21], although one recent study did provide the flowchart as recommended in the CONSORT statement [14]. In general, however, the

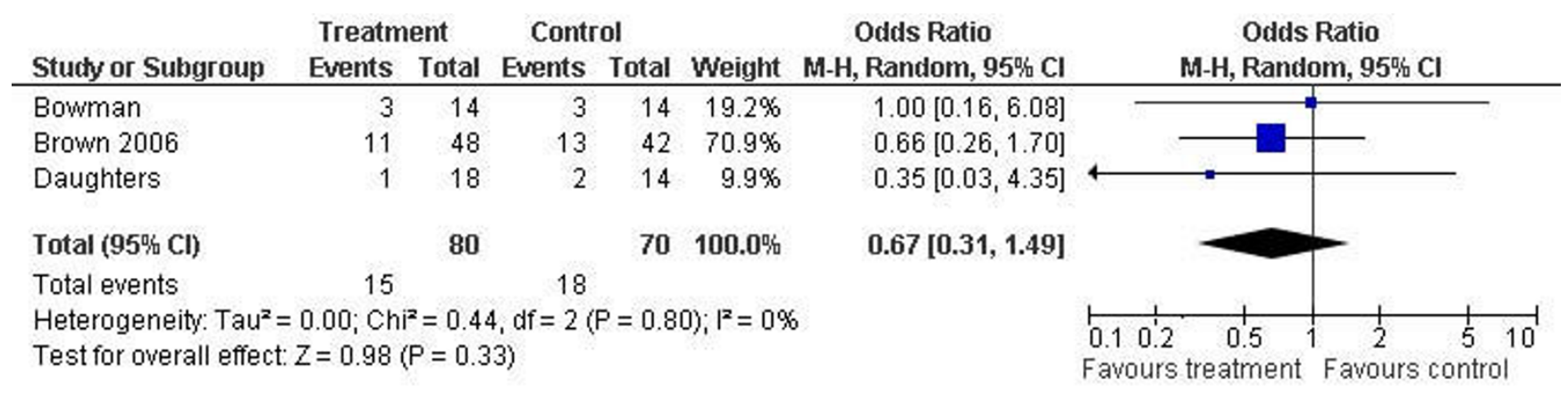

Figure 4

Drop-out from treatment outcomes. Notes: SD: Standard deviation. $Z$ is the Zeta statistic for significance of pooled effect size. $\mathrm{I}^{2}$ is the degree of heterogeneity of the effect size. Cl: Confidence interval. 
reporting of data was adequate and transparent, and outcomes were measured with adequately validated instruments. The main limitation of the studies was the small sample size of all the studies. A serious threat to internal validity of one study in particular was the high attrition of the study by Sandra Brown and colleagues, where less than half the control subjects were included in the followup analyses [13]. This is particularly problematic, as this study is also the single largest trial among all the studies of interventions for co-morbid depressive disorders.

Another key issue concerning the quality of the studies is the criteria for depressive disorders. As can be seen from table 1, the diagnostic criteria vary from elevated scores on self-report questionnaires to CIDI and SCID diagnoses. The studies also varied substantially in terms of setting, types of substances used, and type of interventions. This variability strongly suggests that psychotherapeutic treatments should be considered promising rather than supported for co-morbid substance use disorders and depression.

For anxiety disorders, no meta-analysis could be conducted. However, based on this narrative review there is currently little evidence that offering non-somatic treatment for co-morbid anxiety disorders to patients with substance use disorders will yield any significant benefit; several studies report that outcomes for integrated treatment produced worse results that treatment that focused on substance use disorders alone $[17,20]$. One possible exception is treatment for co-morbid Obsessive-Compulsive Disorder [19], but this is based on a single, very small trial.

At present, there is a need for more and larger trials in order to study the effectiveness of psychological interventions for co-morbid depression and substance use disorders, and a need to develop new treatment options for comorbid anxiety and substance use disorders. Some studies are ongoing (Treatment of co-morbid Depression and Substance Abuse in Young People, NCT00232284; Group Therapy for Women Prisoners With co-morbid Substance Use and Depression, NCT00606996; Outpatient Adolescent Treatment for co-morbid Substance Use and Internalizing Disorders, NCT00438685).

\section{Conclusion}

Psychotherapeutic treatment for co-morbid depression and substance use disorders is a promising approach, it is not sufficiently empirically supported at this point. Psychotherapeutic treatment for co-morbid anxiety and substance use disorders is not empirically supported. There is a need for more trials to replicate the findings from studies of integrated treatment for depression and substance use disorders, and for the development of new treatment options for co-morbid anxiety and substance use disorders.

\section{Competing interests}

The author declares that they have no competing interests.

\section{Authors' contributions}

$\mathrm{MH}$ planned and carried out the review and wrote the manuscript.

\section{Acknowledgements}

This study was funded by intramural funds from the Centre for Alcohol and Drug Research, University of Aarhus.

\section{References}

I. Jané-Llopis E, Matytsina I: Mental health and alcohol, drugs and tobacco: a review of the comorbidity between mental disorders and the use of alcohol, tobacco and illicit drugs. Drug Alcohol Rev 2006, 25(6):5I5-536.

2. Grant BF, Stinson FS, Dawson DA, Chou SP, Dufour MC, Compton W, Pickering RP, Kaplan K: Prevalence and co-occurrence of substance use disorders and independent mood and anxiety disorders: results from the National Epidemiologic Survey on Alcohol and Related Conditions. Arch Gen Psychiatry 2004, 6 I (8):807-8I6.

3. Lubman DI, Allen NB, Rogers N, Cementon E, Bonomo Y: The impact of co-occurring mood and anxiety disorders among substance-abusing youth. Journal of Affective Disorders 2007, I 03(I-3): 105-I I2.

4. Saatcioglu O, Yapici A, Cakmak D: Quality of life, depression and anxiety in alcohol dependence. Drug Alcohol Rev 2008, 27( I):83-90.

5. Tiet QQ, Mausbach B: Treatments for patients with dual diagnosis: a review. Alcohol Clin Exp Res 2007, 3 I (4):5 I 3-536.

6. Hesse M: Achieving abstinence by treating depression in the presence of substance-use disorders. Addictive Behaviors 2004, 29(6): ||37-|| $4 \mid$.

7. Nunes EV, Levin FR: Treatment of depression in patients with alcohol or other drug dependence: a meta-analysis. Journal of the American Medical Association 2004, 29 I (1 5): I887-1896.

8. Hofmann SG, Smits JA: Cognitive-Behavioral Therapy for Adult Anxiety Disorders: A Meta-Analysis of Randomized PlaceboControlled Trials. J Clin Psychiatry 2008, 69(4):62 I-632.

9. Leichsenring F: Comparative effects of short-term psychodynamic psychotherapy and cognitive-behavioral therapy in depression: a meta-analytic approach. Clinical Psychology Review 200I, 2 I (3):40I-4I9.

10. Higgins JPT, Thompson SG, Deeks JJ, Altman DG: Measuring inconsistency in meta-analyses. British Medical Journal 2003, 327(74 | 4):557-560.

II. Bowman V, Ward LC, Bowman D, Scogin F: Self-examination therapy as an adjunct treatment for depressive symptoms in substance abusing patients. Addictive Behaviors 1996, 2 I (I): I 29- I 33.

12. Brown RA, Evans DM, Miller IW, Burgess ES, Mueller TI: Cognitivebehavioral treatment for depression in alcoholism. J Consult Clin Psychol 1997, 65(5):715-726.

13. Brown SA, Glasner-Edwards SV, Tate SR, McQuaid JR, Chalekian J, Granholm E: Integrated cognitive behavioral therapy versus twelve-step facilitation therapy for substance-dependent adults with depressive disorders. Journal of Psychoactive Drugs 2006, 38(4):449-460.

14. Daughters SB, Braun AR, Sargeant MN, Reynolds EK, Hopko DR, Blanco C, Lejuez CW: Effectiveness of a brief behavioral treatment for inner-city illicit drug users with elevated depressive symptoms: the life enhancement treatment for substance use (LETS Act!). Journal of Clinical Psychiatry 2008, 69(I):I22-I29.

15. Markowitz JC, Kocsis JH, Christos P, Bleiberg K, Carlin A: Pilot study of interpersonal psychotherapy versus supportive psychotherapy for dysthymic patients with secondary alcohol abuse or dependence. J Nerv Ment Dis 2008, I 96(6):468-474. 
16. Bowen RC, D'Arcy C, Keegan D, Senthilselvan A: A controlled trial of cognitive behavioral treatment of panic in alcoholic inpatients with comorbid panic disorder. Addictive Behaviors 2000, 25(4):593-597.

17. Randall $C L$, Thomas $S$, Thevos AK: Concurrent alcoholism and social anxiety disorder: a first step toward developing effective treatments. Alcohol Clin Exp Res 200I, 25(2):2 I0-220.

18. Schade A, Marquenie LA, van Balkom AJ, Koeter MW, de Beurs E, Brink $W$ van den, van Dyck $R$ : The effectiveness of anxiety treatment on alcohol-dependent patients with a comorbid phobic disorder: a randomized controlled trial. Alcohol Clin Exp Res 2005, 29(5):794-800.

19. Fals-Stewart W, Schafer J: The treatment of substance abusers diagnosed with obsessive-compulsive disorder: an outcome study. Journal of Substance Abuse Treatment 1992, 9(4):365-370.

20. Hien DA, Cohen LR, Miele GM, Litt LC, Capstick C: Promising treatments for women with comorbid PTSD and substance use disorders. American Journal of Psychiatry 2004, I6 I(8): | 426-1432.

21. Moher D, Schulz KF, Altman DG: The CONSORT statement: revised recommendations for improving the quality of reports of parallel group randomized trials. BMC Medical Research Methodology 200I, I:2.

\section{Pre-publication history}

The pre-publication history for this paper can be accessed here:

http://www.biomedcentral.com/1471-244X/9/6/prepub

Publish with Biomed Central and every scientist can read your work free of charge

"BioMed Central will be the most significant development for disseminating the results of biomedical research in our lifetime. "

Sir Paul Nurse, Cancer Research UK

Your research papers will be:

- available free of charge to the entire biomedical community

- peer reviewed and published immediately upon acceptance

- cited in PubMed and archived on PubMed Central

- yours - you keep the copyright

Submit your manuscript here:

http://www.biomedcentral.com/info/publishing_adv.asp 